so as the observers were not prepared for an accurate observation of the phenomenon.

Thus it appears, without anticipating more accurate observations on the occasion of late eclipses, that the shadow-lines were situated in planes perpendicular to the sun's rays. They moved from the sun.

Singularly enough, neither at Tjilentap nor at the island Lawoengan, was anything of the phenomenon seen. At the island circumstances were very unfavourable, but at Tjilentap the sky was clear.

Batavia, April 28

\section{The Great Storm of June I8}

OUT of a large quantity of hailstones collected here after the storm had subsided, and which were therefore partly melted, I selected one of the largest. The subjoined boundary line is the measure of a section of this hailstone through the poles, the

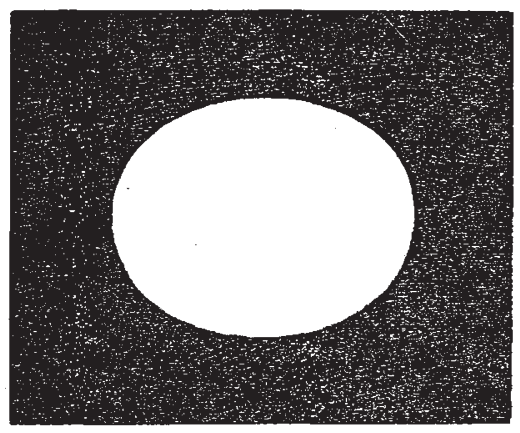

form of it being a prolate spheroid, fiattened on two sides, like a confectionary lozenge, if I may enploy so vulgar a comparison. Many of the hailstones, however, as they fell, were jagged pitces of ice, the like of which I have never seen.

Edgbaston, Birmingham, June 2I

C. M. INGLEBY

\section{Spectrum of Lightning}

I HAD a good view of the spectra of lightning during the storm of yesterday. Frequently there was only one bright line visible, this being coincident with the nitrogen line. At other times there were several bright lines, sometimes with, and at other times without, the nitrogen line. Several flashes showed a continuous sprectrum without visible lines. My instrument was a small direct-vision spectroscope, but sufficiently powerful to divide the sodium line.

Broughton, Manchester, June 19

YESTERDAY this neighbourhood was visited by a most terrific thunderstorm, such as I have never before seen in England. Indeed, it is stated that the last storm of similar severity occurred exactly 33 years ago to a day-rather a singular coincidence. The storm commenced here about half-past one, though distant thunder was audible at one o'clock. It was accompanied by violent wind, rain, and hail, and lasted about an hour, during which $\mathrm{o} 66$ in. of rain fell. The wind was S.E. at the time, but the storm came from the $\mathrm{W}$. The hailstones are described as being, many of them, larger than marbles, and did a good deal of damage to glass. Several fatal accidents have occurred from the lightning, which for some time was almost incessant. I examined its spectrum with a miniature spectroscope, and succeeded in observing four or five lines. Their approximate positions, which I give below, are very roughly determined, and especially so toward the red end. They were obtained by comparison with the Fraunhofer lines, and with the carbon spectrum of a Bunsen burner. The former were mostly very faint from the darkness, but the atmospheric absorption bands near $\mathrm{D}$ were very marked. I am strongly of opinion that the spectrum is that ordinarily given by a spark in air, but was unable to make direct comparison. I have since examined a feeble spark by the same spectroscope, and the general appearance is very similar. I also tried observation of the long zig-zag flashes with a simple prism, but without much success, though I was able to see the spectrum.

H. R. PROCTER

North Shields, June is

$$
\begin{aligned}
& \text { Lines. Wave-length. Remarks. } \\
& \begin{array}{lcl}
\alpha & \text { about } 66 \text { 8th-metres } \\
\beta & , & 59,
\end{array} \\
& \begin{array}{ccccc}
\beta & , & 59 & , & \text { Doubtful } \\
\gamma & , & 56 & , & - \\
\delta & , & 53 & , & \text { Bright. } \\
\epsilon & , & 50 & , &
\end{array}
\end{aligned}
$$

Water Analysis

MY attention has been directed to an article entitled "Water Analysis, I." published in NATURE of June 6. The article is unsigned, bearing neither name nor initials, and contains strange errors and misrepresentations, some of which I beg permission to correct.

First, there is a false date. The article states that in 1868 "Messrs. Chapman, Wanklyn, and Smith proposed to determine the organic matter in water from the amonnt of ammonia evolved when the water was treated with a strongly alkaline solution of potassic permanganate, and then distilled." The truth is, that our paper, proposing the process, and giving directions. how to work it, together with examples, was read before the Chemical Society on June 20,1867 , and published in the Fournal for the year 1867 (vide p. 445, et seq). Moreover, in the year 1867 , our process was extensively employed by the Rivers Commission by Mr. Way, who was at that period the chemist on the Commissior.

Next, I have to notice a misrepresentation. The article de: scribes us as having at first stated that albumen gave up the whole of its nitrogen (in the form of ammonia) when treated with alkaline permanganate, and that afterwards we said that only a certain fraction was obtainable in that way.

We have never said that distillation of albumen with alkaline permanganate converted the whole of the nitrogen of the albumen into ammonia. The assertion in the article is therefore untrue. The circumstance to which your statement was intended to refer was the following.

In our paper read on June 20, 1867, we proposed two distinct modificatiuns of the water process. In the one modification we evaporated to dryness with potash in the oil-bath, and afterwards distilled the residue with alkaline permanganate. The quantity of ammonia got by the operation with potash in the oil-bath, plus the quantity of ammonia got afterwards by permanganate of potash, is cqual or nearly equal to the total ammonia which the total nitrogen of the albumen will yield.

On June 20,1867 , in addition to this early form of the water process, we described and recommended a second modification, consisting in the omission of the evaporation to dryness with potash. We boiled with potash, but did not take down to dryness, and then boiled with permanganate. At that date we knew, and mentioned in the paper, that omission to take down to dryness involved some loss of ammonia which potash should evolve. We did not know that failure to get the full yield with potash involved the ultimate sacrifice of a certain quantity of ammonia. That fact was afterwards ascertained by me, and published later in the autumn of 1867 , and is duly recorded in the Fournal of the Chemical Society.

The conviction that a really serviceable process of wateranalysis mist be a simple one, and the perception that a definite fraction of the total nitrogen was as good a datum as the total nitrogen itself, led me to persist in recommending the second modification rather than the first. Much experience in these matters has confirmed my judgment, and I do not repent the choice that we made.

Returning to the article. After having mentioned our experiments on papaverine, sulphate of cinchonine, narcotine, strychnine, sulphate of quinine, there is the following extraordinary statement :-

"If the authors had enabled us to ascertain the absolute error on the quantity taken instead of the percentage error, by giving us the quantities from which the results were taken, it would no doubt be much more apparent : the results given above in the case of Frankland and Armstrong's paper are absolute errors." I invite you to open the Fournal of the Chemical Society, May r868, which is referred to in our treatise. We did give the quantities from which the results were obtained. Quoting from our memoir, you may read that we took Io mgrm. of papaverine, and obtained $0.22 \mathrm{mgrm}$. of ammonia; that we took $10 \mathrm{mgrm}$. and 5 mgrm. of sulphate of cinchonine, and got respectively 0.57 and 